\title{
Structural behavior of precast Ultra-High Performance Fiber Reinforced Concrete (UHPFRC) cantilever retaining walls: part II — full scale experimental testing
}

\begin{abstract}
One of the main breakthroughs in the concrete technology in the $20^{\text {th }}$ century was the development of Ultra-High Performance Fiber Reinforced Concrete (UHPFRC) as a new generation of sustainable construction material. This paper is presented in two parts. The analysis and design procedures as well as the Environmental Impact Calculations (EIC) of the precast UHPFRC cantilever retaining walls as a sustainable alternative approach to conventional precast Reinforced Concrete (RC) cantilever retaining walls were presented in the first part (Part I) of this paper. In this part (Part II), the reliability of the precast UHPFRC cantilever retaining walls were evaluated through full scale experimental testing. In the experimental tests, four full-scale UHPFRC wall specimens with the dimensions of $2.5 \mathrm{~m}$ in height, $2 \mathrm{~m}$ in length, and $2 \mathrm{~m}$ in width were cast. The area of the steel bars used in the wall stem of the specimens, and the volumetric ratio of the steel fibers used in the UHPFRC mix design were the test parameters. The experimental results proved that the precast cantilever retaining walls manufactured from UHPFRC as a sustainable alternative solution has superior properties in all aspects compared to the conventional precast $\mathrm{RC}$ cantilever retaining wall.
\end{abstract}

Keyword: Ultra-High Performance Fiber Reinforced Concrete (UHPFRC); Steel Fiber Reinforced Reactive Powder Concrete (SFR-RPC); Concrete cantilever retaining walls; Structural behavior; Full-scale experimental tests; Eurocode 7 